San Jose State University

SJSU ScholarWorks

Master's Theses

Master's Theses and Graduate Research

1992

\title{
The confidence of general duty nurses in caring for ethnically diverse inpatient populations within a general hospital setting
}

Charles Wayne Williams

San Jose State University

Follow this and additional works at: https://scholarworks.sjsu.edu/etd_theses

\section{Recommended Citation}

Williams, Charles Wayne, "The confidence of general duty nurses in caring for ethnically diverse inpatient populations within a general hospital setting" (1992). Master's Theses. 435.

DOI: https://doi.org/10.31979/etd.bu5q-mg75

https://scholarworks.sjsu.edu/etd_theses/435

This Thesis is brought to you for free and open access by the Master's Theses and Graduate Research at SJSU ScholarWorks. It has been accepted for inclusion in Master's Theses by an authorized administrator of SJSU ScholarWorks. For more information, please contact scholarworks@sjsu.edu. 


\section{INFORMATION TO USERS}

This manuscript has been reproduced from the microfilm master. UMI films the text directly from the original or copy submitted. Thus, some thesis and dissertation copies are in typewriter face, while others may be from any type of computer printer.

The quality of this reproduction is dependent upon the quality of the copy submitted. Broken or indistinct print, colored or poor quality illustrations and photographs, print bleedthrough, substandard margins, and improper alignment can adversely affect reproduction.

In the unlikely event that the author did not send UMI a complete manuscript and there are missing pages, these will be noted. Also, if unauthorized copyright material had to be removed, a note will indicate the deletion.

Oversize materials (e.g., maps, drawings, charts) are reproduced by sectioning the original, beginning at the upper left-hand corner and continuing from left to right in equal sections with small overlaps. Each original is also photographed in one exposure and is included in reduced form at the back of the book.

Photographs included in the original manuscript have been reproduced xerographically in this copy. Higher quality 6" x 9" black and white photographic prints are available for any photographs or illustrations appearing in this copy for an additional charge. Contact UMI directly to order.

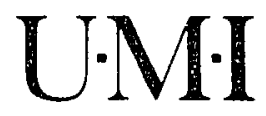

University Microfilms Internatıonal

A Bell \& Howell Information Company

300 North Zeeb Road. Ann Arbor. MI 48106-1346 USA

313:761-4700 800:521-0600 
Order Number 1950129

The confidence of general duty nurses in caring for ethnically diverse inpatient populations within a general hospital setting

Williams, Charles Wayne, M.S.

San Jose State University, 1992

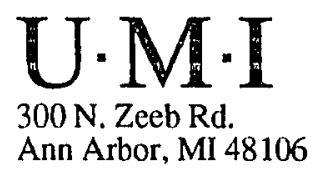




\title{
THE CONFIDENCE OF GENERAL DUTY NURSES \\ IN CARING FOR ETHNICALLY DIVERSE INPATIENT \\ POPULATIONS WITHIN A GENERAL HOSPITAL SETTING
}

\author{
A Thesis \\ Presented to \\ The Faculty of the Department of Nursing \\ San Jose State University \\ In Partial Fulfillment \\ Of the Requirements for the Degree \\ Master of Science
}

By

Charles Wayne Williams

August, 1992 
APPROVED FOR THE DEPARTMENT OF NURSING

$\frac{\text { Luigi Parsons }}{\text { Virgil Parsons. D.N.Sc., R.N. }}$

Bobby Gorefuberg. D.N.Sc.. R.N.

Sharon Hogan

Sharon Hogan, D.N.Sc., R.N

APPROVED FOR THE UNIVERSITY

Th. Lou Lewandowa hi 


\begin{abstract}
THE CONFIDENCE OF GENERAL DUTY NURSES

IN CARING FOR ETHNICALLY DIVERSE INPATIENT

POPULATIONS WITHIN A GENERAL HOSPITAL SETTING

by Charles Wayne Williams
\end{abstract}

This descriptive study, using the "Cultural Self-Efficacy Scale" by Bernal and Froman (1987), measured the degree of confidence that 98 nurses have in their ability to provide culturally specific care to diverse inpatient populations. The highest leveis of confidence for the provision of care were reported for the Hispanic populations. The lowest ratings were reported for the Black and Southeast Asian populations. Low scores were observed on items that included knowledge of health beliefs and practices in addition to beliefs about respect, authority, modesty, sexual education, and HIV counseling. Contrasting with a previous study that investigated the levels of confidence of community health nurses, there were no significant differences in the results of this study. 


\section{ACKNOWLEDGEMENTS}

The author is indebted to many people for their assistance and support in the completion of this study.

To Dr. Virgil Parsons who served as committee chairman, and directed the project, and gave constructive assistance.

To Dr. Bobbye Gorenberg, a co-advisor, who provided ongoing guidance with my course of study at San Jose State University.

A very special thanks to Dr. Julie Corbin, a friend and co-advisor, who provided direction, encouragement, and inspiration throughout the study.

A special thanks to the residents of Royce Hall at San Jose State University for being my support system while studying in the U.S.A. And to the staff of the Emergency Department at Medicine Hat Regional Hospital in Canada for their ongoing support.

The greatest debt of gratitude is owed to my children Jayson, Karrie, and Lori Williams, and Gregory Gilman, a friend, who were supportive and encouraging during my endeavor to obtain a Masters Degree in Nursing. 


\section{TABLE OF CONTENTS}

Page

LIST OF TABLES $\ldots \ldots \ldots \ldots \ldots \ldots \ldots \ldots \ldots \ldots \ldots \ldots$ vii

LIST OF FIGURES. . . . . . . . . . . . . . . . . viii

Chapter

1. INTRODUCTION ........................ 1

Background of the Problem. . . . . . . . . . . . . . . 1

Problem. ......................... 2

Research Questions . . . . . . . . . . . . . . . . . 3

Purpose and Need ..................... 4

Definition of Terms. . . . . . . . . . . . . . . . 5

Summary. ...................... 6

2. CONCEPTUAL FRAMEWORK AND REVIEW OF

LITERATURE. . . . . . . . . . . . . . . 7

Conceptual Framework $\ldots \ldots \ldots \ldots \ldots \ldots \ldots$

Transcultural Nursing Theory . . . . . . . . . . . . . 7

Related Literature . . . . . . . . . . . . . . . . . . 11

Summary. ........................... 15

3. METHOD ........................ 17

Research Design. . . . . . . . . . . . . . . . . . 17 
Instrument $\ldots \ldots \ldots \ldots \ldots \ldots \ldots \ldots \ldots \ldots \ldots \ldots$

Setting and Sample . . . . . . . . . . . . . . 19

Human Subjects Approval. . . . . . . . . . . . . . . 19

Data Collection. ...................... 20

Analysis Procedure $\ldots \ldots \ldots \ldots \ldots \ldots \ldots \ldots \ldots \ldots \ldots$

4. ANALYSIS AND INTERPRETATION OF THE DATA. ....... 22

Description of the Sample. . . . . . . . . . . . . . . 23

Findings $\ldots \ldots \ldots \ldots \ldots \ldots \ldots \ldots \ldots \ldots \ldots \ldots \ldots \ldots$

Analysis Procedure $\ldots \ldots \ldots \ldots \ldots \ldots \ldots \ldots \ldots \ldots, 35$

Summary of Findings. $\ldots \ldots \ldots \ldots \ldots \ldots \ldots \ldots \ldots$

5. CONCLUSIONS AND RECOMMENDATIONS. ......... 38

Conclusions. ..................... 38

Recommendations................... 40

REFERENCES $\ldots \ldots \ldots \ldots \ldots \ldots \ldots \ldots \ldots \ldots \ldots \ldots \ldots \ldots \ldots \ldots$

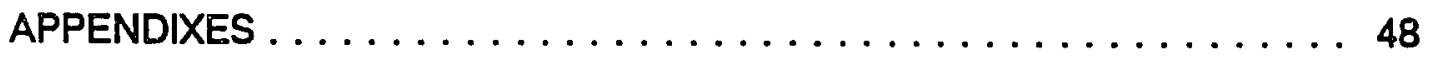

A. Letters of Permission. . . . . . . . . . . . . . . . 49

B. Letter of Consent. . . . . . . . . . . . . . . . . 52

C. Data Collection Instrument .................. 54

D. Consent to Modify Collection Instrument. ........... 60

E. Wayne Stałe University Letter of Consent . . . . . . . . . 62 


\section{LIST OF TABLES}

Table

Page

1. Demographic Characteristics of the

Respondents $(\underline{\mathbb{N}}=98) \ldots \ldots \ldots \ldots \ldots \ldots \ldots \ldots .24$

2. Means and Standard Deviations of the Cultural

Self-Efficacy Scales: Knowiedge of

Cultural Concepts . . . . . . . . . . . . . 25

3. Means and Standard Deviations of the Cilltural

Self-Efficacy Scale--By Ethnic Background:

Knowledge of Cultural Patterns. . . . . . . . . . . . 27

4. Means and Standard Deviations of the Cultural

Self-Efficacy Scale: Skills . . . . . . . . . . . . . . . 29 


\section{LIST OF FIGURES}

Figure

Page

1. Leininger's Sunrise Model .................. 9

2. Lowest Levels of Confidence . . . . . . . . . . . . . . 32

3. Average Levels of Confidence. . . . . . . . . . . . 33 


\section{Chapter 1}

INTRODUCTION

\section{Background of the Problem}

Over the past 5 years, there has been a marked increase in ethnically diverse patient populations. In 1991, the annual inpatient census at a large metropolitan medical center in northern California was 11,065 . Within that population, the ethnic percentage breakdown was Whites $51 \%$, Blacks $4 \%$, Hispanics $27 \%$, and Asians $17 \%$, with the remaining $1 \%$ having no specific ethnic identification. The ethnic inpatient populations at the medical center have increased by $13 \%$ between 1987 and 1991.

The increase can be partially attributed to the number of Blacks, Hispanics, and Asians who have migrated to the larger urban centers within the area. Society has rapidly changed over the past decade due to modern technology, communication, and transportation modes. In most local communities, there are people from mariy different cultures. Likewise, health facilities have clients from virtually every place in the world.

Unfortunately, many health personnel have not moved with these realities to communicate and work effectively with clients from many different cultures (Leininger, 1989). With this influx of migrants, medical centers are required to provide treatment to a more culturally diverse patient population. 
Problem

Nurses working within health care facilities need to provide health care for these diverse populations. Many health care professionals have not been adequately prepared in transcultural health care concepts. In addition, there may be language barriers and different cultural beliefs, which can further cause a communication barrier that basically divides the care giver and the receiver of care. All of the aforementioned factors lead to a decrease in the level of confidence that nurses have in their ability to care for the diversity of clients within the health care facilities.

According to Leininger (1990), there is a major crisis in nursing which is even greatei than the nursing shortage. That crisis is that most nurses are unprepared to function effectively with migrants and cultural strangers. Leininger (1990) contends that there has been a growing problem with cultural imposition and ethnocentrism between nurses and clients and with other health personnel. Cultural imposition was evident as nurses inadvertently or intentionally imposed their values, beliefs, and lifeways onto the client, family, or community groups. This serious problem denies the client his/her culture and ethical rights and often makes the client feel helpless, angry, and frustrated. These feelings give rise to a desire for the client to leave the hospital without treatment. Leininger (1990) further contends that it is difficult for nurses to interpret cultural behavior and to know how best to help culturally diverse 
patients. As a consequence, nurses may experience stress, burnout, and feel inadequate or helpless in their nursing roles.

Research Questions

The research questions addressed in this study were:

1. What is the level of confidence within a sample of nurses who work in an inpatient setting in their ability to make distinctions between key cultural concepts?

2. What is the level of confidence within a sample of nurses who work in an inpatient setting in their ability to care for Hispanic. Black, and Southeast Asian clients?

3. Is there a relationship between selected demographic background variables and the nurses' level of confidence in the ability to provide care for Hispanic, Black, and Southeast Asian clients?

4. Does the level of confidence in nurses' ability to provide care for Hispanic. Black, and Southeast Asian clients vary between the three ethnic groups?

5. Is the level of confidence higher in the sample of nurses who have educational preparation in transcultural concepts in comparison to those nurses who have not been prepared in these concepts? 


\section{Purpose and Need}

The purpose of this study was to determine the levels of confidence that nurses working in an acute health care facility have in their ability to provide culturally sensitive health care to ethnically diverse patient populations. In health care facilities, it is very difficult to find an environment that will promote high levels of confidence in caring for ethnically diverse populations. The actual clinical settings often are absent of role models who are prepared in transcultural nursing (Bernal \& Froman, 1987). The average nurse in these facilities has either a diploma in nursing or a bachelor of science degree in nursing. Most have no specialized preparation in transcultural nursing (Hipps, 1981).

Nurses in these settings have inservice training in various different aspects of health care delivery, and, although the nurses are exposed to ethnically diverse inpatients via daily contact, there is limited inservice training directed to the provision of ethnically specific care. Those nurses who are of different cultures may feel comfortable with patients from their own culture but not necessarily comfortable with those from other cultures (Burner, Cunningham, \& Hattar, 1990).

Assessing the level of confidence that nurses have caring for different ethnic populations is the first step in a process directed towards improving the quality of nursing care (Leininger, 1984). Nurses should identify their levels of 
confidence in the understanding of cultural beliefs and the needs of ethnically diverse populations. This identification is needed if nurses are to interact professionally and provide ethnically specific health care (Leininger, 1984). Nurses can then use this information to develop interventions that will assist in improving their ability to meet the culturally sensitive health care needs of ethnically diverse patient populations.

\section{Definition of Terms}

For this study, the following definitions of terms apply:

1. Hispanic is the term assigned to those populations who have origins in the country of Mexico. This determination was made based upon data collected from the medical center. The data indicated that those Hispanic patients who had been discharged from the medical center at the time of this study were all of Mexican origin.

2. Blacks are those populations who trace their ancestry to members of the Negroid race in Africa.

3. Southeast Asians are those populations who had origins in the countries of Vietnam and Cambodia.

4. Level of Confidence is the degree of confidence as measured by the Cultural Self-Efficacy Scale, that nurses providing health care to Hispanic, Black, and Southeast Asian clients have in their ability to provide culturally sensitive care. 
5. Nurses are registered nurses who provide care for Hispanic, Black, and Southeast Asian patients.

6. Demographic Variables are the variables of age, number of years in nursing, educational level, cultural orientation, area of nursing specialty, and number of different clinical settings worked in since graduation.

7. Ability to provide care refers to the ability of the nurse to provide culturally sensitive care, applying the concepts of transcultural nursing.

Summary

This study has implications for the delivery of health care by nurses to ethnically diverse patient populations. The Cultural Self-Efficacy Scale (CSES) can be used as a means of identifying cultural awareness and levels of confidence that nurses have in their ability to deliver care to ethnically diverse patient populations. The conceptual framework for this study and the literature review will be discussed in Chapter 2 . 


\section{Chapter 2}

\section{CONCEPTUAL FRAMEWORK AND REVIEW OF RELATED LITERATURE \\ Conceptual Framework}

This chapter presents the conceptual framework of the study, which is based on a transcultural nursing theory. Also described is a review of the literature concerning the problem under investigation.

Transcultural Nursing Theory

Concepts which formed the conceptual framework for this study were drawn from Leininger's theory of Transcultural Nursing. Included were the concepts of cultural care diversity and universality. Leininger (1978) defined transcultural nursing as a formal area of study and practice focused on the cultural beliefs, values, and lifeways of diverse cultures and on the use of this knowledge to provide culturally specific or culturally universal care to individuals, families, and groups of particular cultures.

Leininger (1984) holds that care and health differ with cultural cognitions, values, and practices among cultures, with some identifiable universal features. Social features (e.g., religion, kinship, economic, and cultural values) are closely related to health care values and practices. These features influence or account for health care differences and similarities (Leininger, 1984). Leininger (personal communication, March 6, 1992) contends that it is not enough for 
nurses to be aware that cultural differences exist, but that nurses need to identify those differences and to seek assistance in the delivery of culturally sensitive care.

Culturally meaningful and efficacious nursing care is contingent upon the use of culturally derived ethnographic data for health and care (Leininger. 1984). In order for the nurse to provide culturally sensitive care to a client, the use of ethnonursing practices must be incorporated into the nursing process. Leininger (1984) defines ethnonursing as a culturally cognitive approach designed to be assistive and facilitative to individuals, families, and cultural groups. The application of ethnonursing will assist in the development and provision of care that is congruent with clients' values, norms, and practices. There are three major types of ethnonursing care and actions in therapeutic health practices: (a) care accommodation, (b) care preservation and/or maintenance, and (c) care repatterning.

The conceptual model that depicts these ethnonursing care and actions is Leininger's Sunrise Model (see Figure 1). This model symbolizes "the rising of the sun (care)" (Giger \& Davidhizar, 1990). The model is depicted as a rising sun with four levels of foci and can be used by nurses to discover cultural values and to assist in the understanding of what care means to people of various cultures. Within the circle at the upper portion of Figure 1 are components of the social structure and world view factors that influence care 


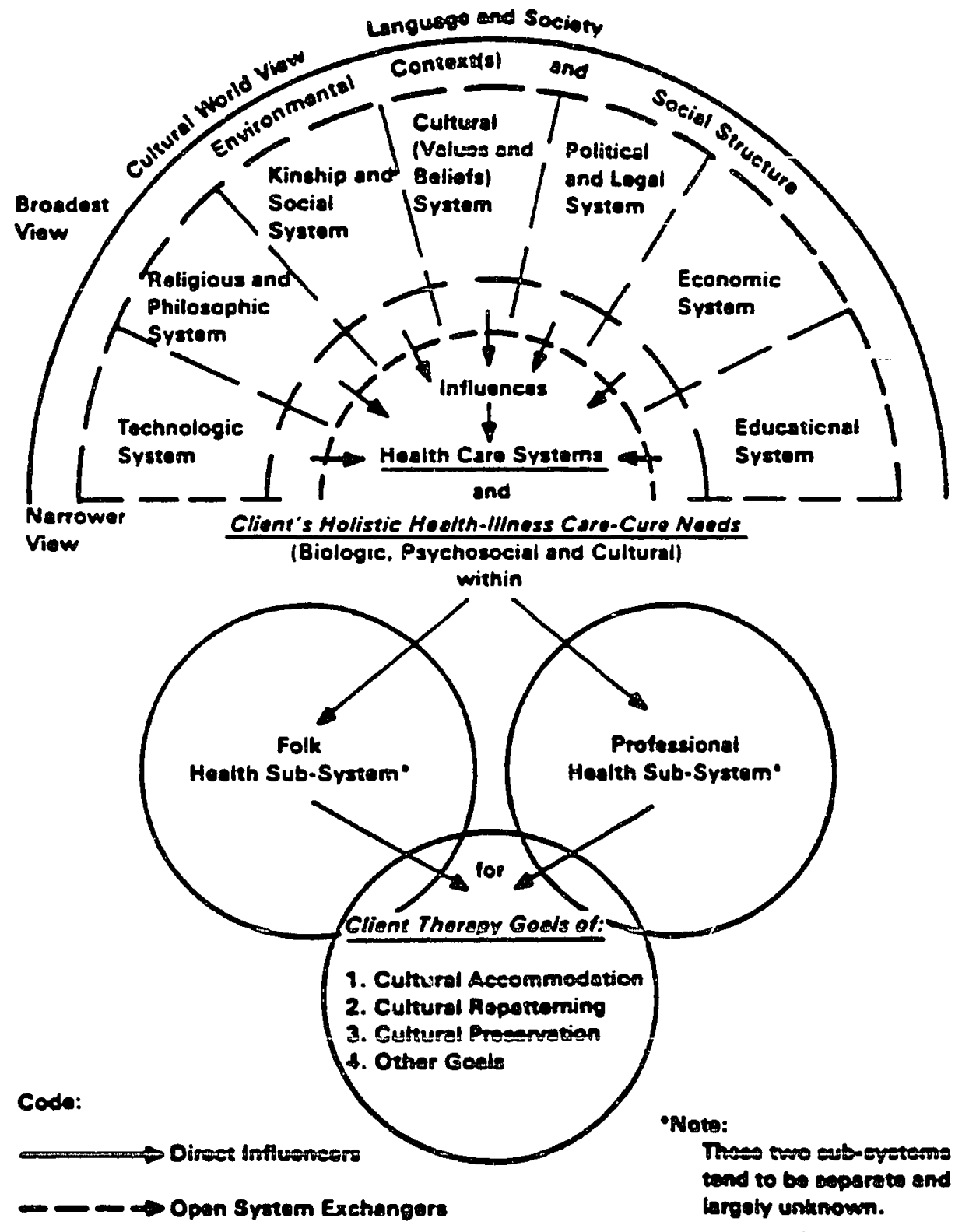


and health through language and environment. Leininger (1984) contends that these factors influence folk, professional, and nursing systems or subsystems located in the lower half of Figure 1 as depicted by three interlocking circles. Leininger depicts the blending of the Folk Health Subsystem and Professional Health Subsystem within two individual circles that interlock with a third circle, depicting the Client Therapy Goals of cultural accommodation, cultural repatterning, cultural preservation, and other goals (see Figure 1). At each level within the model, various cultural phenomena are studied from the micro. middle, and macro perspective (Giger \& Davidhizar, 1990).

The first assumption of Leininger's theory is that culturally based care values, beliefs, and practices are essential to human growth, living, and survival. This assumption is depicted in the third level of the sunrise model. Within the third level, the following subsystems are represented: (a) technological, (b) religious and philosophical, (c) kinship and social, (d) cultural, (e) political and legal, ( $f$ economic, and $(g)$ educational systems (Figure 1 ).

Leininger's second assumption focuses on the identification of factors that influence the seven subsystems of the cultures of the provider of care and the receiver of care. If nurses who provide care to culturally diverse patient populations use the Sunrise Model in the assessment phase of the nursing process, the possibility of culturally sensitive care exists. 
Leininger (1984) contends that nurses using the Sunrise Model to learn the beliefs and practices of other cultures and assess for interventions will have greater confidence levels in their ability to provide the needed care. In addition, the nurses will be better prepared to provide culturally sensitive care.

\section{Related Literature}

A review of literature revealed many published studies that describe the concepts of transcultural care. However, only one study has been published that investigated the levels of confidence that nurses have in providing care to ethnically diverse client populations. In a study entitled "The Confidence of Community Health Nurses in Caring for Ethnically Diverse Populations" (Bernal \& Froman, 1987), the degree of confidence in caring for three ethnic populations (Blacks, Latino/Hispanics, and Southeast Asians) was identified. The researchers concluded that nurses within the sample did not report a high level of confidence about caring for any of the three identified ethnic groups within the community setting.

Leininger (1962), in a study entitled "The Gadsup of New Guinea and Early Child-Caring Behaviors with Nursing Care Implications," studied the cultural patterns and values of the Gadsup including their health-illness and caring modalities. She concluded from the study that one must understand a total way of living together, other than an individualized one. The study further identified a need for the health care professional to learn the beliefs and the 
lifelong caring and curing practices of different cultures in order to provide culturally sensitive care.

Wauneka (1962) studied the beliefs and customs of the Navajo nation. The study focused on providing tuberculosis education to the tribe. Wauneka concluded that in order to provide successiul health education to the Navajo, it was necessary to understand the beliefs and health practices of the tribe.

Tsung Tzu Louie (1974) studied the process of explanatory thinking and culturaliy reiaied concepts of health and illness in the Chinese-American illness situation. Tsung Tzu Louie indicated that health practitioners should first familiarize themselves with the cultural concepts of health and illness of the population they are serving. Only then is the professional in a position to assess the patient's bicultural illness concept and offer intervention.

French and Schwartz (1973) studied two clients from different cultures as they progressed through the terminal phases of their illness. They concluded that health professionals often fail to recognize how much culture affects the way patients and their family seek treatment and respond to medical personnel. The researchers further concluded that when a nurse is giving care to a family whose lifestyle is molded by a different culture, the underlying beliefs of the client and family members which influence behavior can often be identified by the caregiver. 
In their book, Ethnic Nursing Care: A Multicultural Approach, Orque, Bloch, and Monrroy (1983) refer to transcultural nursing as ethnic nursing care. They further explain that this type of care entails 'the nurses' effective integration of the patient's ethnic cultural background into nursing process-based patient care" (p. 7).

Friedman (1990) proposed that in order for nurses to effectively provide care to ethnic groups, a transcultural perspective must be incorporated. The author also stressed the importance of evaluating and understanding client behavior in the social and cultural context in which it occurs. In a study entitled "Ethnic Power Perspectives for Nursing," the traditional sources of family power were identified (Marchione \& Stearns, 1990). These researchers concluded that it is helpful to consider both the traditional power values of the specific ethnic group and the current values of the dominant society when nurses are providing care.

DeSantis (1988) contends that in order for nurses to be transcultural. they must temporarily step out of their own traditions so that they can perceive and understand a situation in a culturally different environment and implement specific interventions when and where practical and ethical. Doku (1990), in an article entitled "Approaches to Cultural Awareness," stated that those planning services and taking care of the ill have failed to recognize that this society is becoming more culturally diverse. Doku also contends that there is a need for 
understanding of and sensitivity towards cultural differences when planning services, and staff training cannot be overemphasized. It is the duty of every nurse to strive for competence by learning about clients' cultural, ethnic, and religious backgrounds. If clients do not understand the nursing care being delivered, the nurse cannot deliver care effectively (Doku, 1990).

Other researchers (Anderson \& Tighe, 1969; Osborne, 1969; Ragucci. 1971: Williams, 1971) have conducted studies with various cultures. The outcome of each research project has been the conclusion that nurses need to learn about the culture for which they are providing care. Also, nurses need to apply that knowledge to the nursing process in order to provide culturally specific care. Leininger (1990) noted that in a profession that seeks to involve the patient in his or her own care, nothing can be more important than understanding the patient's heritage and traditions.

In addition to the research cited, other descriptive articles in the literature spoke to the effects of confidence and self-efficacy. Bandura (1981), in his article, "Self-Efficacy Mechanisms of Agency," stated that individuals become more confident in their ability to complete tasks if they are familiar with all aspects of the task to be completed and if they are also familiar with other factors which contribute to the successful completion of that task. This increased confidence may then lead to a greater level of confidence in the person's ability to perform the task. 
Bandura (1977) has described self-efficacy as a person's sense of confidence that a particular behavior can be carried out. According to Bandura (1977, 1981), individuals use four sources of information in forming perceptions of self-efficacy or confidence about particular tasks: (a) performance of the task itself; (b) vicarious experiences or information derived from observing others; (c) verbal persuasion or praise; and (d) emotional or physiological factors such as arousal, comfort, or pain. A factor that influences feelings of confidence in community health nurses about caring for ethnically distinct clients includes the opportunity to work with such clients. In addition, nurses must have appropriate role models from which they may observe positive behaviors. receive praise and encouragement, and be in a receptive physical and mental state to care for these clients (Bernal \& Froman, 1987). Bandura (1977. 1981) also stresses that there is a definite correlation between the level of confidence people have in their ability to complete a task and their understanding of the variables which contribute to the completion of the task.

\section{Summary}

Although transcultural literature is extensive, there has not been a study published dealing with the levels of confidence that nurses have who work in an inpatient setting and their ability to care for culturally diverse patient populations. This study proposed to explore this topic. The need for nurses to be prepared in the concepts of transcultural nursing concepts may lead to increased levels 
of confidence on the part of the nurses to provide culturally specific care to ethnically diverse patient populations.

This review of literature leads to five major questions:

1. What is the level of confidence within a sample of nurses who work in an inpatient setting in their ability to make distinctions between key cultural concepts?

2. What is the level of confidence within a sample of nurses who work in an inpatient setting in their ability to care for Hispanic, Black, and Southeast Asian clients?

3. Is there a relationship between selected demographic variables and the nurses' confidence in the ability to provide care for Hispanic. Black, and Southeast Asian clients?

4. Does the level of confidence in the nurses' ability to provide care for Hispanic, Black, and Southeast Asian clients yary between the three groups?

5. Is the level of confidence higher in the sample of nurses who have educational preparation in transcultural concepts in comparison to those nurses who have not been prepared in these concepts? This study proposed to answer these questions. 


\section{Chapter 3}

METHOD

This chapter presents the methodology for this study of the levels of confidence of general duty nurses in caring for ethnically diverse patient populations within a general hospital setting. It describes both the questionnaire used and the manner in which it was prepared and administered.

Research Design

The design of this study followed the principles of survey research, in that the participants were asked to complete a questionnaire. The assessment fool was the Cultural Self-Efficacy Scale (CSES) developed by Bernal and Froman in 1987 (Appendix A) and tested in a study that measured the confidence of community health nurses in their ability to provide care to an ethnically diverse population. In addition to the CSES, the participants were asked to complete a demographic profile.

Instrument

The questionnaire was a 37 item, Likert-type self-efficacy tool for measuring the levels of confidence that nurses have in their ability to provide care for ethnically diverse inpatient populations (Appendix A). Bernal and Froman (1987) derived the original 30 questions from anthropological and transcultural nursing literature, representing key concept knowledge and skills in 
transcultural nursing care. The original tool was modified with the permission of Bernal and Froman (Appendix B) to reflect the nursing functions in an acule care facility. In addition, seven questions were added by the researcher to include additional duties of acute care nurses.

The scale items were grouped into three sections according to (a) knowledge of key cultural concepts associated with transcultural nursing. (b) knowledge of cultural patterns within the Black, Hispanic, and Southeast Asian groups, and (c) ability in performing nursing skills based on knowledge of the Black, Hispanic, and Southeast Asian groups. The conceptual groupings within these categories were health beliefs and practices, life-style patterns and practices, and cultural sensitivity. The respondents were asked to rate their level of knowledge concerning each category of the cultural concepts and to rate their level of knowledge concerning the cultural patterns of each of the three groups. Finally, they were asked to rate their ability to perform nursing skills based on their knowledge of each of the three ethnic groups. The self-efficacy ratings ranged from "Very little confidence" to "Quite a lot of confidence," scored on a range of 1 to 5 . High ratings on the scale indicate that the respondents have high levels of confidence in their ability to deliver culturally appropriate care to the three ethnic groups. Nurses who score high would be likely to engage in delivering care to these populations. Low ratings 
indicate that nurses do not have confidence in their ability to deliver culturally appropriate care and thus may avoid working with these ethnic groups.

The reliability of the Cultural Self-Efficacy Scale was demonstrated by the developers to have a coefficient alpha equal to .97 . This tool is reported by its authors to have been tested to demonstrate high construct and content validity (Bernal \& Froman, 1987).

\section{Setting and Sample}

The study was conducted in northern California. The subjects were obtained from an urban medical center. The medical center was a 539 bed. acute care facility located in a large ethnically diverse county with a population of over 1.5 million people.

The subjects represented a convenience sample selected on the basis of being a registered nurse practicing at the medical center. The sample consisted of 98 nurses who were employed in the Medical-Surgical, Maternal-Child, and Acute Care units of the medical center.

\section{Human Subjects Approval}

The rights of the participants were protected. After receiving human subjects approval from the medical center and Institutional Review Board, Human Subjects, at San Jose State University (Appendix C), the participants were supplied with a brief description of the study and given the opportunity to volunteer or refuse to participate in the study. Participation in the study implied 
consent (Appendix D). Participants were informed of their right to withdraw from the study at any time without prejudice to them. In addition, each participant was assured complete anonymity. Participants were informed that results of the study would be made available upon request.

Data Collection

Each of the 125 questionnaire packets contained three components. The first component was a consent letter which outlined the purpose of the study and the procedures. This section also outlined the appropriate persons to contact in the event that the participants had other concerns which were not addressed in the letter of consent (see Appendix E). The second component was a demographic questionnaire which solicited information such as age, number of years in nursing, educational background (Associate degree, Bachelor's degree, or a Masters degree in Nursing), ethnicity, and preparation in transcultural nursing concepts (see Appendix C). The third component was the Cultural Self-Efficacy Scale (CSES) assessment tool (see Appendix A).

The five page packets were placed in envelopes and distributed to the nursing units at the medical center. Enclosed in each packet were envelopes which were labeled "Research Questionnaire." The respondents were instructed to complete the questionnaire and to place it in a box which was located on each of the nursing units. 
The Director of Nursing Administration informed each of the nursing unit managers about the study and the distribution of the questionnaires to the staff. The investigator was available in person and by telephone to address any questions or concerns of the participating nurses.

Responses were placed in the collection boxes over a 2 week period in March, 1992. They were collected until an additional 1 week had passed without any further questionnaires being placed in the boxes. The survey process was then considered to be completed, and analysis of the returned questionnaires began.

\section{Analysis Procedure}

The data were subjected to Alpha reliability testing to determine the means, standard deviations, and internal consistency of the responses. A multiple regression was calculated to predict the overall scores on the CSES. Descriptive analysis and Pearson $\mathrm{r}$ correlational analysis were used in the statistical computations. The findings and analysis are presented in Chapter 4. 


\section{Chapter 4}

\section{ANALYSIS AND INTERPRETATION OF THE DATA}

This chapter presents a description of the sample and the study's findings that answer the following five questions:

1. What is the level of confidence within a sample of nurses who work in an inpatient setting in their ability to make distinctions between key cultural concepts?

2. What is the level of confidence within a sample of nurses who work in an inpatient setting in their ability to care for Hispanic, Black, and Southeast Asian clients?

3. Is there a relationship between demographic variables and the nurses' level of confidence in the ability to provide care for Hispanic, Black, and Southeast Asian clients?

4. Does the level of confidence in nurses' ability to provide care for Hispanic, Black, and Southeast Asian clients vary between these three groups?

5. Is the level of confidence higher in the sample of nurses who have educational preparation in transcultural concepts in comparison to those nurses who have not been prepared in these concepts? 
Description of the Sample

Of the 125 questionnaire packets which were distributed, $98(78 \%)$ were returned. The demographic data of the sample can be found in Table 1. The mean age of the respondents was 36.1 years, while the years out of nursing school reflected an average of 9.5 years. The ethnic backgrounds of the nurses who responded were: White $62 \%$, Black $8 \%$, Hispanic $14 \%$, Asian $14 \%$, and Other $2 \%$. The 10 respondents who indicated additional educational preparation in transcultural nursing were separated from those that did not have educational preparation. This procedure ensured that the results did not reflect higher levels of confidence in the overall sample of nurses.

Findings

The following section reviews the findings for each of the five questions in the study:

\section{Statistical Analysis of Question 1}

The mean scores and standard deviations were calculated for the levels of confidence that nurses had in their ability to distinguish key cultural concepts (Table 2). There was very little deviation seen in the levels of confidence in knowledge of key cultural concepts. The means ranged from 2.3 to 2.4 with a standard deviation ranging between .9 to 1.1 . 
Table 1

Demographic Characteristics of the Respondents ( $N=98)$

\begin{tabular}{|c|c|c|}
\hline Age: $(M=37)$ & $\begin{array}{l}\text { Number of } \\
\text { Respondents }\end{array}$ & $\begin{array}{l}\text { Percentage of } \\
\text { Respondents* }\end{array}$ \\
\hline 20 to 30 years & 30 & 30 \\
\hline 31 to 50 years & 63 & 64 \\
\hline 51 to 60 years & 5 & 5 \\
\hline \multicolumn{3}{|l|}{$\begin{array}{l}\text { Educaíional } \\
\text { Preparation } \\
\end{array}$} \\
\hline$A D$ & 39 & 39 \\
\hline B.S.N. & 57 & 58 \\
\hline M.S.N. & 3 & 3 \\
\hline \multicolumn{3}{|l|}{$\begin{array}{l}\text { Years Out of } \\
\text { School }(M=9.5)\end{array}$} \\
\hline 1 to 5 years & 23 & 23 \\
\hline 6 to 10 years & 47 & 48 \\
\hline 11 to 20 years & 21 & 21 \\
\hline 20 or more years & 7 & 7 \\
\hline \multicolumn{3}{|l|}{ Ethnic Background } \\
\hline White & 60 & 62 \\
\hline Black & 8 & 8 \\
\hline Hispanic & 14 & 14 \\
\hline Asian & 14 & 14 \\
\hline Other & 2 & 2 \\
\hline
\end{tabular}


Table 1 (continued)

Demographic Characteristics of the Respondents ( $N=98)$

\begin{tabular}{lcc}
\hline $\begin{array}{l}\text { Transcultural } \\
\text { Nursing Ed. }\end{array}$ & $\begin{array}{l}\text { Number of } \\
\text { Respondents }\end{array}$ & $\begin{array}{l}\text { Percentage of } \\
\text { Respondents }\end{array}$ \\
\hline Yes & 10 & 10 \\
No & 88 & 90 \\
\hline
\end{tabular}

*Percentages may not total 100 because of rounding.

Table 2

Means and Standard Deviations of the Cultural Self-Efficacy Scales:

Knowledge of Cultural Concepts ( $N=98$ )

\begin{tabular}{|c|c|c|c|}
\hline Item Number & Item Description & $M$ & SD \\
\hline 1 & $\begin{array}{l}\text { Inter/Intra Cultural } \\
\text { Diversity }\end{array}$ & 2.3 & 0.9 \\
\hline 2 & $\begin{array}{l}\text { Ethnocentrism and } \\
\text { Discrimination }\end{array}$ & 2.4 & 1.1 \\
\hline 3 & Ethnicity and Culture & 2.4 & 1.0 \\
\hline
\end{tabular}


Statistical Analysis of Question 2

The mean scores and standard deviations were calculated for the levels of confidence that nurses who work in an inpatient setting have in their ability to care for Black, Hispanic, and Southeast Asian clients (Tables 3 \& 4). The means for the nurses' level of confidence in their knowledge of the cultural patterns of Black, Hispanic, and Southeast Asian clients ranged from 2.4 to 2.5 for all three ethnic groups. The standard deviation ranged from 1.1 to 1.4.

The highest mean level of confidence ratings was found for the Hispanic group, with the average overall ratings of 2.3 for the following: (a) migration patterns. (b) class structure, (c) patterns of disease, and (d) family organization. The means for level of confidence ratings for the Black group ranged from a low of 2.1 for knowledge of traditional folk health practices to a high of 2.7 for the following: (a) family organization and (b) gender roles. The means for level of confidence for the Southeast Asian group ranged from 2.2 for the following: (a) traditional folk health practices, (b) migration, (c) class structure, and (d) patierns of disease to a high of 2.7 for family organization.

Items that had average level of confidence scores lower than 2.5 across all of the ethnic groups included the following: (a) use of the health care system. (b) social support, (c) traditional folk health practices, (d) migration patterns, (e) class structure, (f) employment patterns, (g) patterns of disease, 


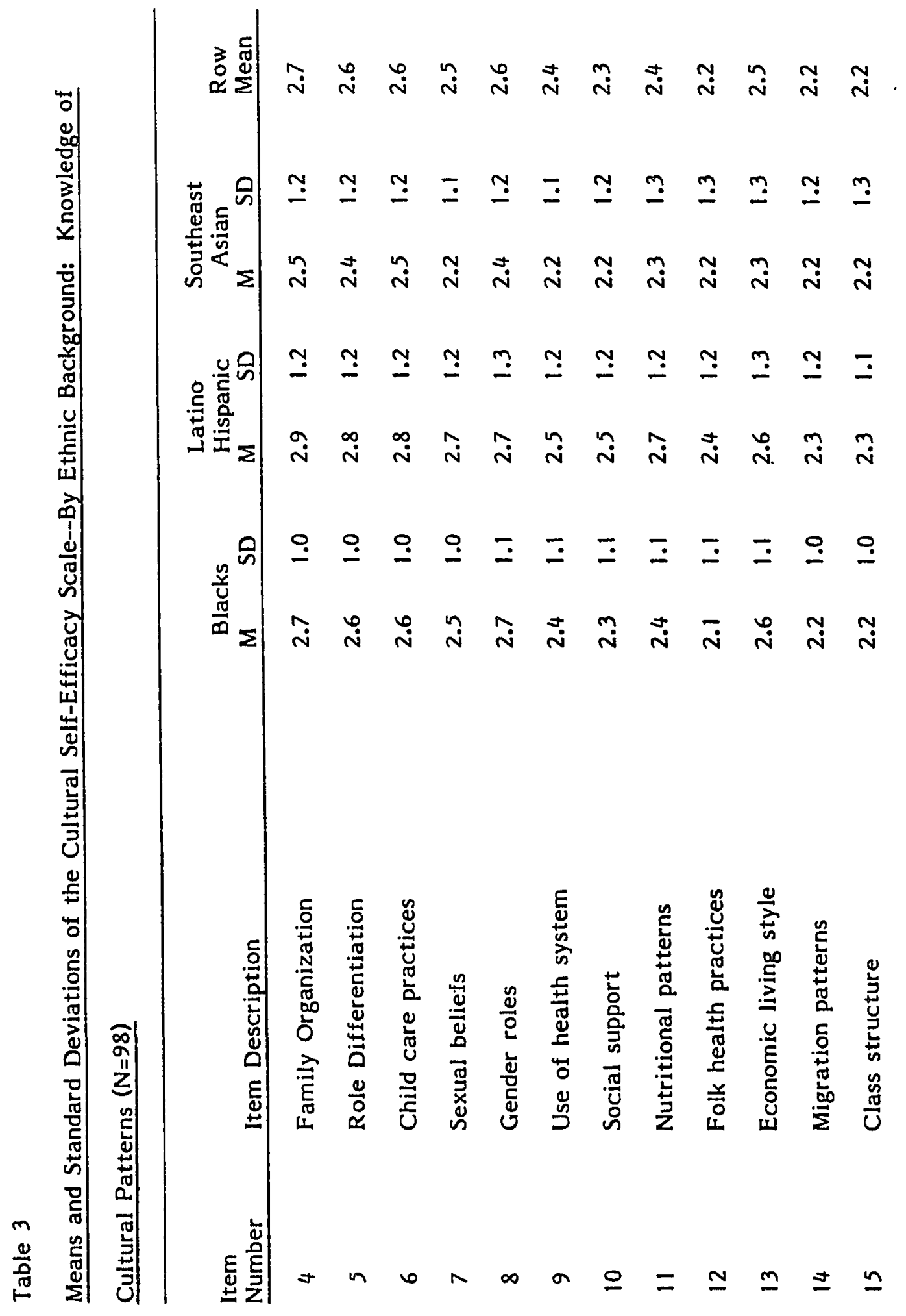




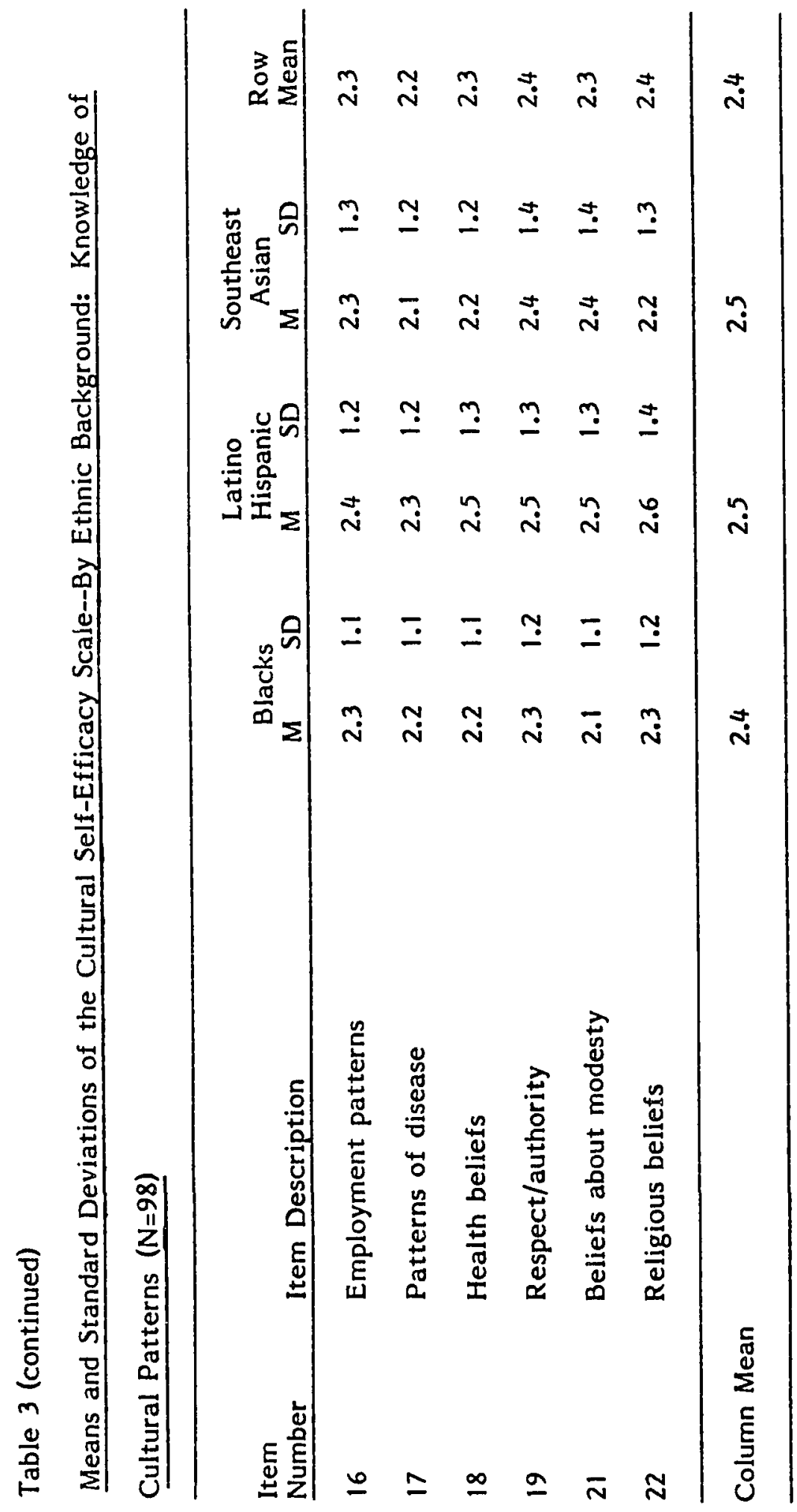




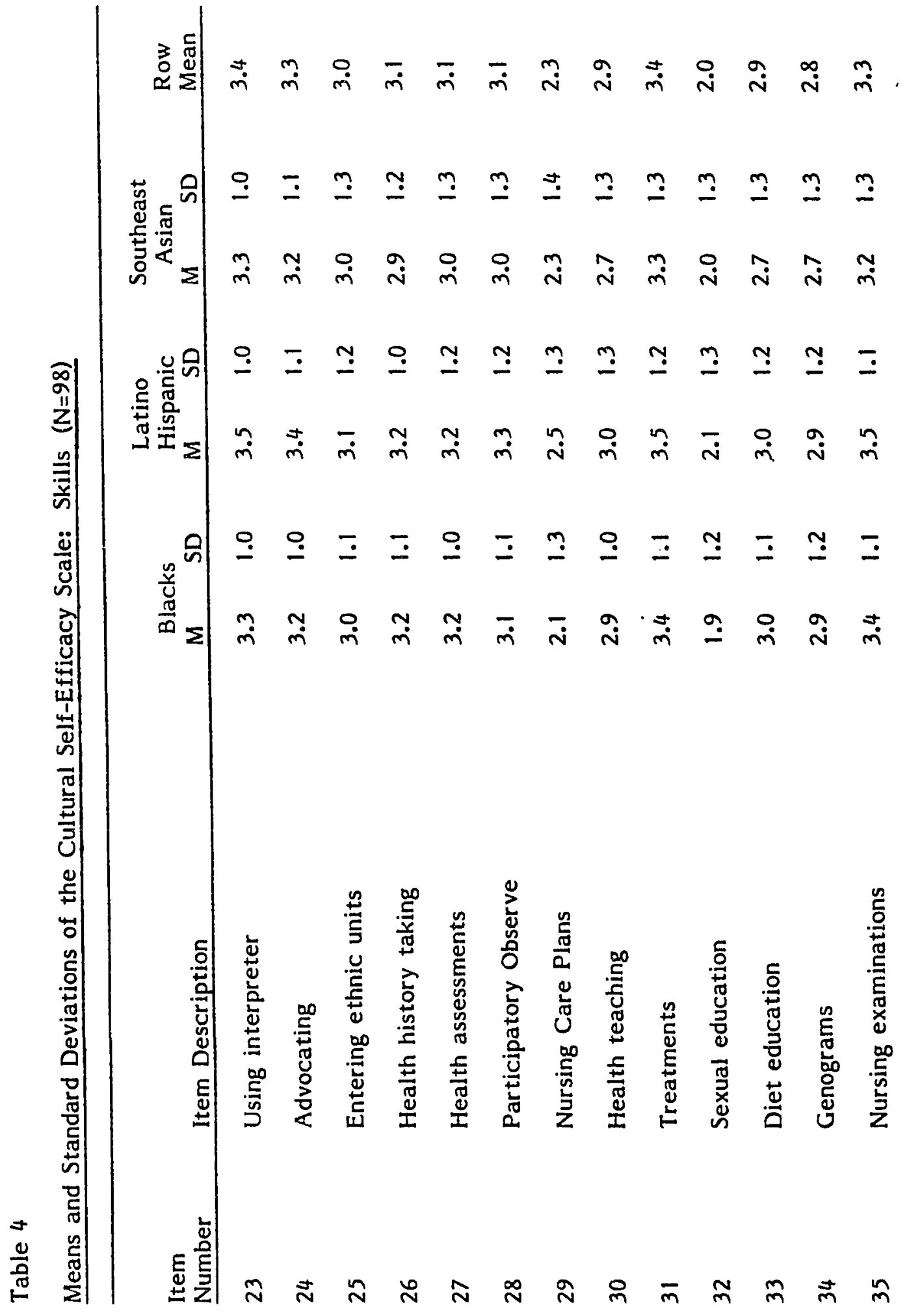




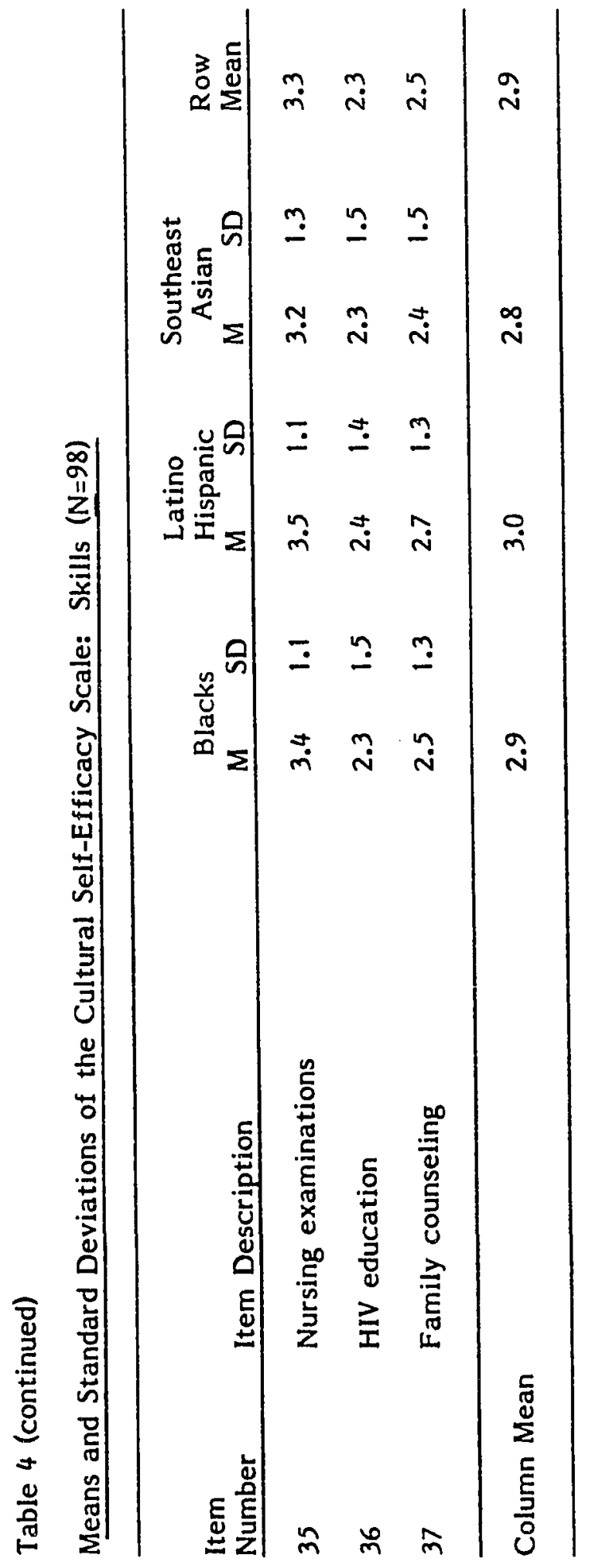


(h) health beliefs, (i) beliefs concerning respect and authority, and (j) beliefs about modesty (see Figure 2).

The second part of Question 2 dealt with the levels of confidence that nurses who work in an inpatient setting have in their ability to perform nursing skills based on their knowledge of the three ethnic groups. The means for the nurses' level of confidence ranged from 2.8 to 3.0 (Table 4). The standard deviation ranged from 1.0 to 1.5 .

The highest means for level of confidence ratings were found for the Hispanic group, with the average ratings of 2.5 for developing nursing care plans, to a high of 3.5 for the following skills: (a) using an interpreter, (b) providing treatments, and (c) carrying out a nursing examination. The means for level of confidence ratings for the Black group ranged from a low of 2.1 for developing nursing care plans, to a high of 3.4 for treatments. The means for level of confidence for the Southeast Asian group ranged from a low of 2.3 for the provision of HIV education and developing nursing care plans to a high of 3.3 for the use of an interpreter and treatments. Items that had average level of confidence scores lower than 2.5 across all of the ethnic groups included the following: (a) developing nursing care plans, (b) providing sexual education, (c) providing HIV counseling, and (d) family health education (see Figure 3). 


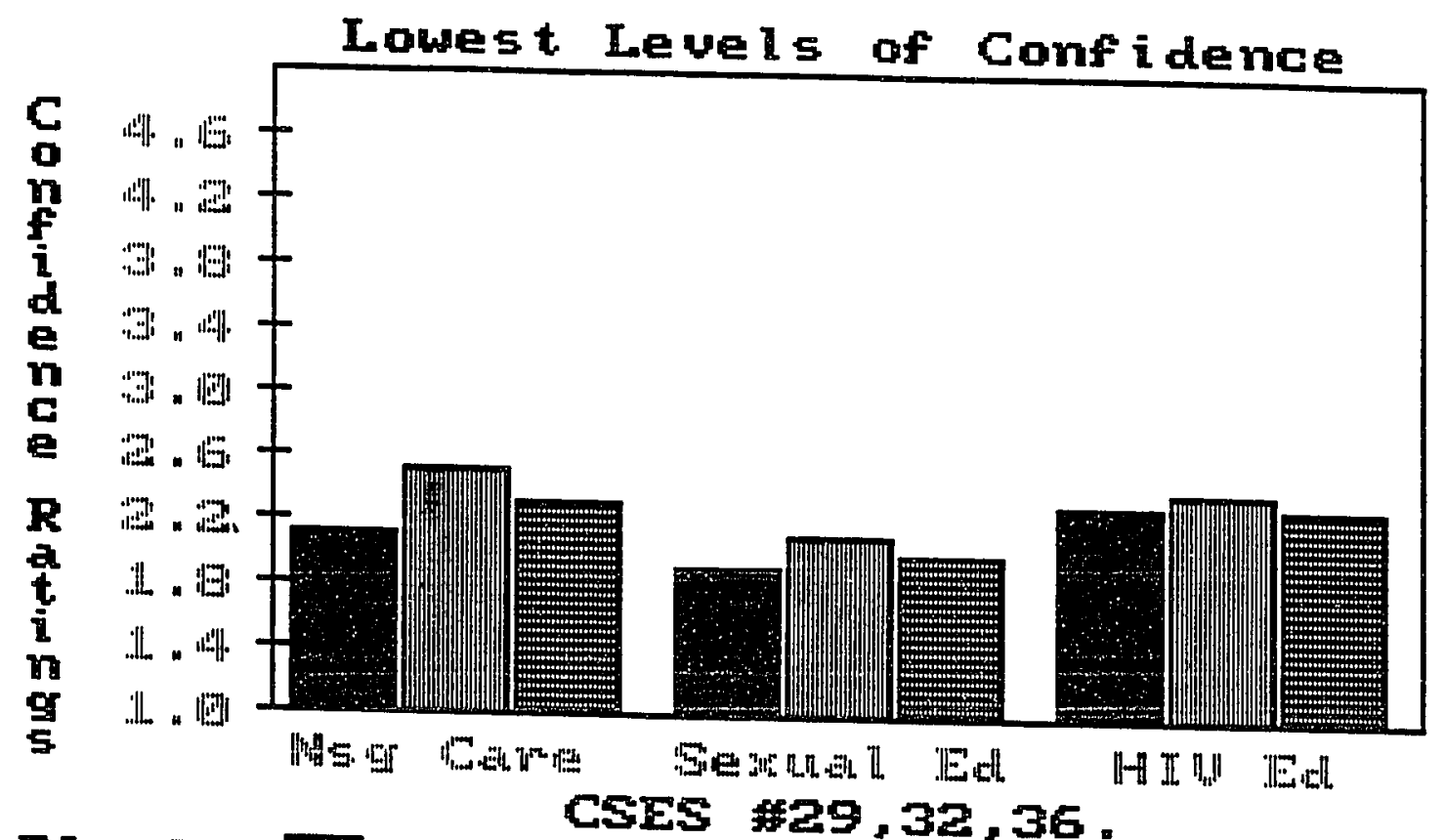

Blacks Hispanics Din Asians

Figure 2. Lowest Levels of Confidence. 


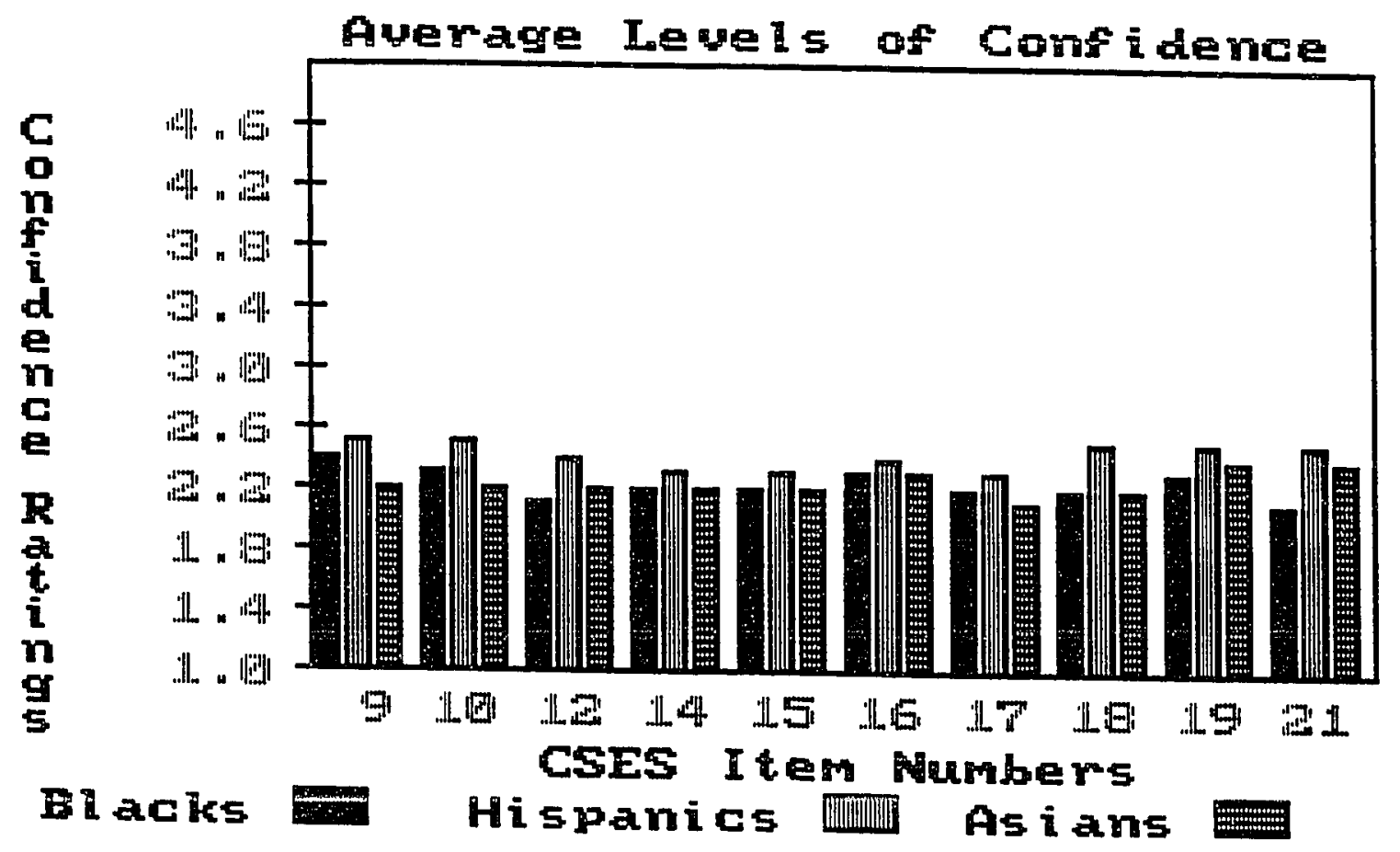

Figure 3. Average Levels of Confidence. 


\section{Statistical Analysis of Question 3}

The demographic data were correlated with the mean scores for level of confidence for all categories. None of the correlations was significant. The age of the respondent did not have a correlation with a higher or lower level of confidence. The educational preparation or the number of years out of nursing school did not indicate a stronger or weaker level of confidence in the nurses' ability to care for the three ethnic groups. Also, the ethnic background did not indicate a greater level of confidence to care for the ethnic groups. The fact that nurses may be Hispanic. Black, or Asian did not increase their level of confidence in taking care of patients from their own ethnic background or from other backgrounds.

\section{Statistical Analysis of Question 4}

The levels of confidence of the nurses to provide care for the Black, Hispanic, and Southeast Asian clients did not vary significantly between the groups. The ratings range between 2.1 to 3.5 on the CSES. The midpoint of the 3 may be interpreted as a neutral or noncommittal rating of confidence (Bernal \& Froman, 1987). A rating of 2 is verbally anchored as "little confidence" on the scale. There were no levels of confidence that reached a 4 on the scale for any of the three ethnic groups. Had there been, they would have translated to a "moderate level of confidence." Therefore, all the scores 
indicated neutral or noncommittal ratings of confidence in the nurses' ability to care for Hispanic, Black, and Southeast Asian patients in an inpatient setting. Statistical Analysis of Question 5

The levels of confidence in the sample of nurses who have educational preparation in transcultural nursing concepts were higher than those nurses without this preparation. The mean level of confidence in the nurses' ability to distinguish key cultural concepts was 4.2. The mean level of confidence in the nurses' knowledge of cultural patterns for each of the three groups--Blacks, Hispanics, and Southeast Asian--was 4.1, 4.2, and 4.2, respectively. The mean level of confidence in the nurses' ability to perform nursing skills for each of the three groups, Blacks, Hispanics, and Southeast Asians, was 4.0, 4.3, and 4.2, respectively.

\section{Analysis Procedure}

The collected data were subjected to Alpha reliability testing to determine the means and standard deviations. The alpha internal consistency estimates for the entire scale were found to be .97 for all sets of data. The standard error of measurement was 1.0. A multiple regression calculated to predict overall scores on the Cultural Self-Efficacy Scale was 0.5 . This score did not reach statistical significance. An R of .13 using the four demographic variables accounted for only $1 \%$ of the total variance in self-efficacy ratings. The multiple 
regression and internal consistency estimates matched those of the 1987 study (Bernal \& Froman).

$$
\text { Summary of Findings }
$$

\section{Question 1}

The ratings for the first question in this study ranged around the midpoint of 3 on the CSES. The midpoint indicating neutral or noncommittal levels of confidence in the nurses' ability to distinguish key cultural concepts.

\section{Question 2}

The ratings for the second question indicated that there was no significant difference in the nurses' ability to identify cultural patterns and to perform nursing skills for the three groups, Blacks, Hispanics, and Southeast Asians.

\section{Question 3}

The ratings for the third question indicated that there was no predictive difference in the nurses' ability to provide care to the three groups, Blacks, Hispanics, and Southeast Asians, based on demographic variables.

\section{Question 4}

The ratings for the fourth question indicated that there was no significant difference in the level of confidence between the three ethnic groups. Blacks, Hispanics, and Southeast Asians. 


\section{Question 5}

The ratings for the fifth question indicated that there was a significant difference between the levels of confidence for nurses who have been prepared in transcultural nursing concepts and those nurses who have not been prepared.

These results will be discussed in Chapter 5 to render conclusions and recommendations that articulate with the conceptual framework of this study. 
Chapter 5

\section{CONCLUSIONS AND RECOMMENDATIONS \\ Conclusions}

This study implies that nurses who work with ethnically diverse inpatient populations in an inpatient setting have neutral or noncommittal levels of confidence in their ability to care for these patients. There is a strong indication that even when nurses are from the same ethnic groups as their patients, the nurses tend to deliver care which is grounded in ethnocentrism. This further supports the contentions of Leininger (1986) that nursing education programs have not prepared students to care for clients from other cultures. Or, if nursing students are prepared, they may not carry those concepts into their nursing practice. When enrolled in nursing education programs, students tend to be subjected to ethnocentrism beliefs concerning the delivery of health care. and this exposure in turn affects the way they will practice.

When individuals feel a weak sense of confidence for a task, they will avoid that task; when faced with failure, they will show little task commitment. In contrast, if the sense of confidence is strong, individuals will approach a task, acquire new behavior related to the success of the task, and persist in the event of initial failure (Stretcher et al., 1986). This study indicated that the nurses have a weak sense of confidence with respect to transcultural nursing. 
and this will contribute to avoiding the tasks or relying on nursing education approaches that may be grounded in ethnocentrism.

This study indicated that nurses were not comfortable with the key cultural concepts such as: (a) inter and intra cultural diversity, (b) ethnocentrism and discrimination, and (c) ethnicity and culture. The nurses were not able to make adequate distinctions between the concepts that refiected high levels of confidence. While the levels of confidence for the knowledge of cultural patterns were low, the nurses' levels of confidence were higher in their ability to perform nursing skills. This difference may indicate that nurses are comfortable in carrying out nursing tasks but not in a culturally sensitive nature.

The demographic data indicated that there were no significant differences in the ability of the nurses to score higher levels of confidence in the knowledge of cultural patterns based on age, basic nursing education, years of nursing, or ethnic orientation. However, within the 10 questionnaires which indicated preparation in the concepts of transcultural nursing concepts, the mean scores were higher across all items. For this group, the mean score for knowledge of cultural concepts was 4.2 , while the means for knowledge of cultural patterns and nursing skills based on knowledge of ethnic groups were 4.5 and 4.2, respectively. These scores reflect a moderate level of confidence in the ability of the nurse to provide culturally sensitive care. Although the scores were 
higher than those nurses without transcultural nursing concepts, there is still a need for improvement.

\section{Recommendations}

More research in this area is needed, and it should include a larger sample of nurses and be extended to include more acute care facilities. If nurses are to provide culturally sensitive care to ethnically diverse inpatient populations, they will need to have preparation in transcultural nursing care.

It is also recommended that nursing education programs integrate the concepts of transcultural nursing in their curricula and provide students with an opportunity to provide care for ethnically diverse populations. The nursing faculty also need to ensure that the students identify cultural differences and implement care which is culturally sensitive. The provision of care alone is not adequate unless the student understands why the required care is different.

It is further recommended that hospitals implement cultural educational programs for staff nurses. These programs should include strategies that assist staff in the identification of cultural differences and in the development of nursing care plans which reflect the cultural needs of their clients. In addition, resource persons that have been prepared in transcultural nursing concepts need to be available for consultation to the nursing staff. These resource persons could develop inservice programs for the staff that deal with the 
concepts of transcultural nursing and assist the staff to develop methods to deliver culturally sensitive care.

Transcultural nursing education will provide nurses with the knowledge and cultural understanding necessary to implement the nursing process in a culturally sensitive manner. Nurses will be prepared to develop nursing care plans that reffect the cultural needs of their clients. Educational preparation in transcultural nursing concepts will also refiect an increased sense of self-efficacy. which is needed by the nurses who provide care to ethnic groups. As a result of this preparation, nursing care will be grounded in cultural understanding and appreciation of differences instead of being severely limited by ethnocentrism. 


\section{REFERENCES}




\section{References}

Andrews, M. M., \& Ludwing, P. A. (Eds.). (1984). Nursing practice in a kaleidoscope of cultures. Unpublished doctoral dissertation, University of Utah College of Nursing, Utah.

Anderson, G., \& Tighe, B. (1973). Gypsy culture and health care. American Journal of Nursing, 73(2), 283-285.

Bandura, A. (1977). Self-efficacy: Toward a unifying theory of behavioral change. Psychology Review, 84, 191-215.

Bandura, A. (1981). Self-efficacy mechanisms of agency. American Psychologist, 37, 22-47.

Bandura, A. (1984). Recycling misconception of perceived self-efficacy. Cognitive Therapy and Research, 35, 125-139.

Bernal, H., \& Froman, R. (1987). The confidence of community health nurses in caring for ethnically diverse populations. Image: Journal of Nursing Scholarship, 19(4), 201-203.

Brink, P. J. (1976). Transculîural nursing. Englewood Cliffs, NJ: Prentice-Hall. Burner. O. Y.. Cunningham, P., \& Hattar, H. S. (1990). Managing a multicultural nurse staff in a multicultural environment. JONA, 20(6), 30-34.

Chrisman, N. J. (1990). Cultural shock in the operating room: Cultural analysis in transcultural nursing. Journal of Transcultural Nursing, 1(2), 33-35. 
DeSantis, L., (1988). The relevance of transcultural nursing to international nursing. International Nursing Review. 35(4), 110-116.

Doku, J. (1990). Approaches to cultural awareness. Nursing Times, 86(39), 6970.

Dougherty, M. C., \& Tripp-Reimer, T. (1985). The interface of nursing and anthropology. In B. J. Siegal (Ed.). Annual review of anthropology (pp. 219241). Palo Alto, CA: Annual Reviews.

French, J., \& Schwartz, D. R. (1973). Terminal care at home in two cultures. American Journal of Nursing, $\underline{73}, 502-505$.

Friedman, M. M. (1990). Transcultural family nursing: Application to Latino and Black families. Journal of Pediatric Nursing. $\underline{5}(3), 214-222$.

Giger, J., \& Davidhizar, R. (1990). Transcultural nursing assessment: A method for advancing nursing practice. International Nursing Review, 37(1), 199202.

Graedon, T. F. (1985). A transcultural approach to nursing practice. In J. E. Hall \& B. R. Weaver, Distributive nursing practice: Systems approach to community health (3rd ed.) (pp. 315-331). Philadelphia: Lippincott.

Hipps, O. (1981). The integrated curriculum: The emperor is naked. American Journal of Nursing, 81(5), 976-981.

Leininger, M. (1984). The essence of nursing and health. Detroit: Wayne State University Press. 
Leininger, M. (1970). Nursing and anthropology: Two worlds to blend. New York: John Wiley \& Sons.

Leininger, M. (1978). Transcultural nursing: Concepts, theories and practices. Now York: John Wiley \& Sons.

Leininger, M. (1990). The transcultural nurse specialist: Imperative in today's world. Nursing \& Health Care, 10(5), 251-256.

Leininger, M. (1981). Intercultural interviews, assessment and therapy implications. In Pederson. P. (Ed.), Interviews and assessments. Beverly Hills, CA: Sage.

Leininger, M. (1980). Caring: A central focus for nursing and health care services. Nursing and Health Care. 1(3), 135-143, 176.

Leininger, M. (1990). Ethnomethods: The philosophic and espitamic bases to explicit transcultural nursing knowledge. Journal of Transcultural Nursing. $1(2), 40-51$.

Leininger, M. (1989). A new generation of nurses discover transcultural nursing. Nursing and Health Care, $\underline{8}(5), 30-35$.

Logan, B. B., \& Dawkins, C. E. (1986). Family-centered nursing in the community. Menlo Park, CA: Addison-Wesley.

Marchione, J.. \& Stearns, S. J. (1990). Ethnic power perspectives for nursing. Nursing and Health Care, 11(6), 296-301. 
Orque, M. S., Bloch, B., \& Monrroy, L. A. (1983). Ethnic nursing care: A multicultural approach. St. Louis, MO: Mosby.

Osborne, O. (1969). Anthropology and Nursing: Some common traditions and interest. Nursing Research, 18(3), 251-255.

Parse, R. (Ed). (1988). Leininger's theory of nursing: Cultural care diversity and universality. Nursing Science Quarterly, 1(4), 152-160.

Ragucci, A. T. (1972). The ethnographic approach and nursing research. Nursing Research, 21(6), 485-490.

Spector, R. E. (1985). Cultural diversity in health and illness (2nd ed.). Norwalk, CT: Appleton-Century-Crofts.

Thomas. D. N. (1981). Black American patient care in transcultural health care. In G. Henderson \& M. Primeaux (Eds.), Transculturai health care (pp. 209223). Menlo Park, CA: Addison-Wesley.

Thomas, S. B. (1990). Community health advocacy for racial and ethnic minorities in the United States: Issues and challenges for health education. Health Education Quarterly. 17(1). 13-19.

Tripp-Reimer, T., \& Lauer, G. M. (1987). Ethnicity and families with chronic illness. In L. M. Wright \& M. Leahey (Eds.), Families and chronic illness (pp., 77-100). Springhouse, PA: Springhouse. 
Tsung Tzu Louie, T. (1974). Explanatory thinking in Chinese-Americans. In P. J. Brink (Ed.). Transcultural nursing: A book of readings (pp. 240-246). Englewood Cliffs, NJ: Prentice-Hall.

Wauneka, A. D. (1962). Helping a people to understand. American Journal of Nursing, 62(7), 88-90.

Williams. M. A. (1971). Ethnocultural response to hysterectomy: Implications for nursing. In P. J. Brink (Ed.), Transcultural nursing: A book of readings (pp. 219-233). Englewood Cliffs, NJ: Prentice-Hall. 
APPENDIXES 
APPENDIX A

Letters of Permission 
Appendix A

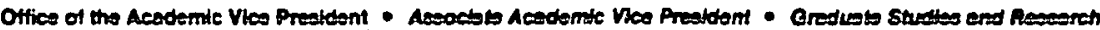

One Wasnington Square - San Jose'. Cellifomia $85192-0025 \cdot 408 / 924-2480$

To: Charles Wayne Williams, Nursing

355 South 8th Street Rm 325

San Jose, CA 95122-3664

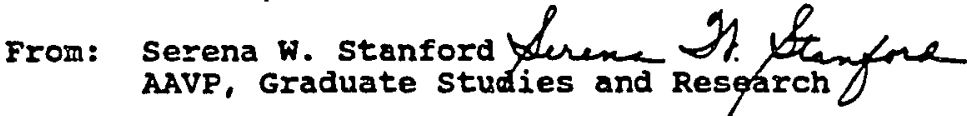

Date: February 17, 1992

The Human Subjects-Institutional Review Board has approved your request to use human subjects in the study entitled:

"The Confidence of General Duty Nurses in Caring for Ethnically Diverse Patient Populations within a General Hospital Setting"

This approval is contingent upon the subjects participating in your research project being appropriately protected from risk. This includes the protection of the anonymity of the subjects' identity when they participate in your research project, and with regard to any and all data that may be collected from the subjects. The Board's approval includes continued monitoring of your research by the Board to assure that the subjects are being adequately and properly protected from such risks. If at any time a subject becomes injured or complains of injury, you must notify $\mathrm{Dr}$. Serena stanford immediately. Injury includes but is not limited to bodily harm, psychological trauma and release of potentially damaging personal information.

Please also be advised that each subject needs to be fully informed and aware that their participation in your research project is voluntary, and that he or she may withdraw from the project at any time. Further, a subject's participation, refusal to participate or withdrawal will not affect any services the subject is receiving or will receive at the institution in which the research is being conducted.

If you have questions, please contact me at 408-924-2480.

CC: Juliet M. Corbin, Nursing 
Shirley Iysm

Director

Nursing Administration

February 6, 1992

TO: Patient Care Directors and Supervisors

FROM: Shirley Iynn

SUBJECT: Research Profect

Dr. Julie Corbin, Ph.D. R.N. from San Jose State University has referred Charies Williams, R.N. B.N., to me for assistance in doing a research project on "The Confidence of General Duty Nurses In Caring For Ethnically Diverse Patient Populations Within A General Hospital Setting". I would like us to make every effort to accomodate him. I have attached for your information the list of questions he'll be asking the nurses. He assures me It will take only a few minutes and he will not be disruptive to the unit. My thought was that he could catch nurses on their break somewhere on the unit (CC Conference Room, sON Conference Room, etc.) He has targeted March 1 to March 15 for this: 'please call my volce mail and leave a message on your reaction to his request. Again, please serfously consider assisting him.

Maintaining coliegial ties with San Jose state university is a high priority.

SI/bd

Attachment 
APPENDIX $\mathrm{B}$

Letter of Consent 
20 SANYOSE

Appendix B

2115 UNAVERSTY

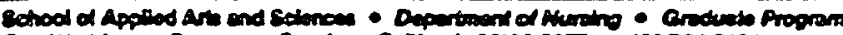

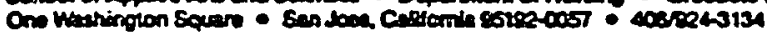

GENERAL hOSPITAL NURSING UNITS

Subject's Consent

TITLE OF PROJECT: The Confidence of General Duty Nurses In Caring For Ethnically Diverse Patient

Populations Within A General Hospital Seting.

PURPOSE: The purpose of this proposed study is to determine the level of confidence, that nurses who work in the clinical setting of a general hospital have in caring for ethnically diverse patient populations.

PROCEDURE:

If you decide to participate, you will complete the attached questionnaire and return it in the enclosed envelope. It will iake approximately 15 minutes.

RISKS/DISCOMFORTS: There are no known $r$ isks associated with your participation in the study. Your responses are confidential. Should you feel uncomfortable about the questionnaires, you may contact me at $408-824-8542$

BENEFITS :

By participating in this study, you will be contributing to knowledge concerning the degree of confidence that nurses who cross cultural barriers have as they provide care. We cannot and do not guerantee or promise that you will receive any benefits irom this study. A summary of the findings will be made available to all participants.

ALTERNATIVES :

You are under no obligation to take part in this study, and you may refuse to do so if you wish; you wa withdraw from the sudy at any time.

costs:

Your participation in this atudy is on a voluntary basis and does not involve any cost to you. 
APPENDIX C

Data Collection Instrument 
Appendix C

Code :

DEMOGRAPHIC DATA

1. Age :

2. NUMBER OF YEARS IN NURSING:

3. EDUCATIONAL LEVEL IN NURSING:

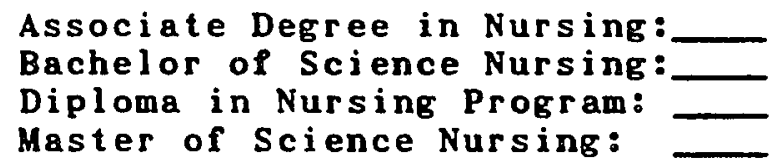

4. HOW MANY DIFFERENT INSTITUTIONS HAVE YOU WORKED IN SINCE YOUR GRADUATION FROM A NURSING PROGRAM:

5. WHAT IS YOUR ETHNIC/CULTURAL ORIENTATION:

6. NURSING SPECIALITY:

7. SHIFT WORKED IN YOUR FACILITY:

8. POST BASIC NURSING EDUCATION IN "TRANSCULTURAL NURSiNG" YES : _ NO: IF YES TO NUMBER 7 , WHAT TYPE OF EDUCATION: 


\section{PLEASE NOTE}

Copyrighted materials in this document have not been filmed at the request of the author. They are available for consultation, however, in the author's university library.

$56-59$

University Microfilms International 
APPENDIX D

Consent to Modify Collection Instrument 
Appendix D

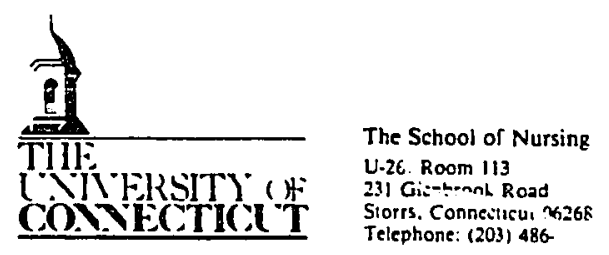

January 23,1991

Mr. Charles Wayne Williams

P.B. 721061

San Jose, California $95172=1061$

Dear Mr. Williams:

With respect to your request for permission to use the The Cultural self-Efficacy scale, I an happy to give you that permission.

With respect to the changes you propose, let me say that while they seem logical for your setting, the reliability and valdity data that we have provided for the original tool would not apply to the revised tool. You would need to repeat these procedures (i.e. Cronbach's Alpha for internal consisitency) and report this in your study. In addition, the factor analysis would need to be repeated in order to see whether the same underlying conceptual structure remains with the additional tasks that you propose.

Good luck with your research and please share that results with us.

sincerely,

Annueta Bencal

Henrietta Bernal RN, Ph.D.

Associate Professor 
APPENDIX E

Wayne State University Letter of Consent 


\section{Appendix E}
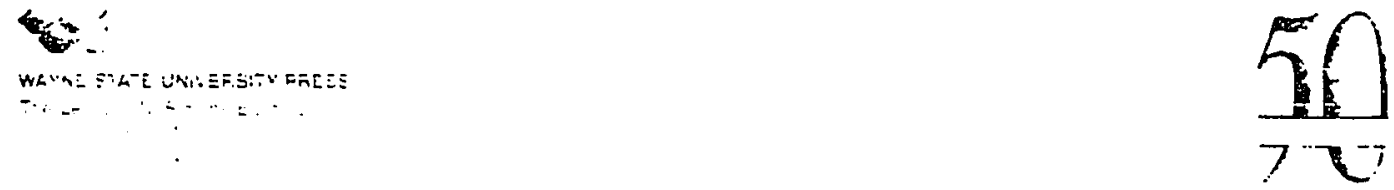

March 31, 1992

Mr. Charles Wayne Williams

P.0. Box 721061

San Jose, CA 95172-1061

Dear Mr. Williams:

As requested, you are hereby granted permisston to reproduce, without charge, FIgure 11-1, wh1ch appears on p. 137 of Care: The Essence of Nursing and Health, in your unpublished thesis.

of course, proper acknowledgment must be clted.

sincerely,

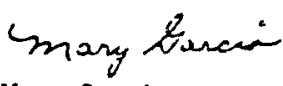

Mary Garcia

Permissions Editor

mg 